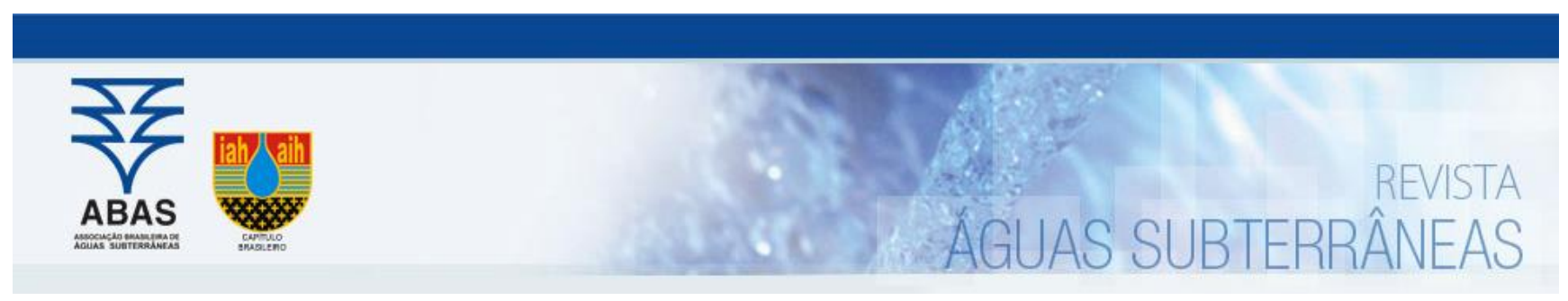

Artigos

\title{
Influência da interação rio-aquífero sobre a distribuição vertical da meiofauna hiporreica
}

\section{Influence of the river-aquifer interaction on the vertical distribution of hyporheic meiofauna}

\author{
Jonathas Barbosa de Araújo Freitas'; Jaime Joaquim da Silva Pereira Carbal1; Anderson Luiz Ribeiro de Paiva1; Tatiane \\ Barbosa Veras ${ }^{1}$; Rafael Vinícius de Albuquerque Monteiro ${ }^{1} \bowtie$ \\ 1 Grupo de Recursos Hídricos, Departamento de Engenharia Civil, Universidade Federal de Pernambuco (UFPE), Recife, PE \\ $\triangle$ jonathasfreitas77@gmail.com, jcabral.ufpe@gmail.com, andersonlrpaiva@gmail.com, tatiane_veras@yahoo.com.br, rafael_pe30@hot- \\ mail.com
}

\section{Palavras-chave:}

Interação água subterrânea-água superficial.

Zona hiporreica.

Meiofauna.

Hidrodinamismo.

Fluxo vertical do rio.

Keywords:

Groundwater-surface water interaction. Hyporheic zone.

Meiofauna.

Hydrodinamism.

River vertical flow.

Revisado por pares.

Recebido em: 01/04/2019.

Aprovado em: 09/09/2019.

Resumo

Entre os processos de autopurificação natural que ocorrem na zona hiporreica, estão os de aspecto biológico, onde os organismos da meiofauna desempenham importantes funções, favorecendo a melhoria da qualidade da água de recarga do aquífero subjacente ao rio. São diversos os fatores que influenciam a distribuição vertical da comunidade meiofaunística como o hidrodinamismo na massa hídrica superficial e a disponibilidade de matéria orgânica e oxigênio nas camadas mais profundas. Por isso, este artigo objetivou avaliar a influência destes dois fatores na distribuição vertical da meiofauna hiporreica em três pontos do rio Beberibe-PE. O hidrodinamismo foi considerado como resultado direto do regime pluviométrico e o fluxo vertical entre o rio e o aquífero foi analisado a partir de medições realizadas em três períodos pluviométricos distintos com auxílio do piezômetro diferencial. A análise da distribuição vertical da meiofauna foi realizada a partir do levantamento da abundância média em camadas de $2 \mathrm{~cm}$ até a profundidade de $10 \mathrm{~cm}$. Foram contabilizados 4906 indivíduos pertencentes a 8 grupos taxonômicos. Os resultados mostraram que as camadas superficiais foram as mais abundantes. Entretanto, a diminuição desta abundância não se deu gradativamente com a profundidade, provavelmente por uma vazão maior do rio no período chuvoso e/ou por condições de rio influente. Apesar de que estes fatores não demonstraram um caráter completamente determinante sobre a distribuição vertical.

Abstract

Among the processes of natural autopurification that occur in hyporheic zone, there are those of biological aspect, where meiofauna organisms play important functions, favoring the quality improvement of the recharge water of the river underlying aquifer. There are several factors that influence the vertical distribution of meiofaunal community such as hydrodynamism in surface water and the availability of organic matter and oxygen in deeper layers. Therefore, this article aimed to evaluate the influence of these two factors on the vertical distribution of hyporheic meiofauna in three points of the Beberibe river, in Pernambuco State, Brazil. Hydrodinamism was considered a direct result of the rainfall regime and the GW-SW flow was analyzed through measurements made in three different rainfall periods with the aid of differential piezometer. The analysis of meiofauna vertical distribution was carried out from the survey of the average abundance in layers of $2 \mathrm{~cm}$ to the depth of $10 \mathrm{~cm}$. A total of 4906 individuals belonging to 8 taxonomic groups were accounted. The results showed that the superficial layers were the most abundant. However, the decrease of this abundance did not occur gradually with depth, probably due to a greater flow rate of the river in the rainy season and/or by descending flow river conditions. Although these factors did not demonstrate a completely determinant character on the vertical distribution.

DOI: http:/dx.doi.org/10.14295/ras.v33i4.29528

\section{INTRODUÇÃO}

Vários aspectos da interação rio-aquífero têm sido estudados nas últimas décadas. Isto é reflexo da relevância destas duas massas hídricas que são as principais fontes de fornecimento de água potável para a população e importante recurso também para a indústria e agricultura (BARA et al., 2014).

Neste cenário, entre as diversas temáticas a respeito da interação rio-aquífero, a zona hiporreica merece ser destacada como um ecossistema de grande influência nessa interação, sendo responsável por um conjunto de reações importantes (VERAS et al., 2017).

A zona hiporreica é a zona de interação entre a água superficial e a água subterrânea. Caracteriza-se por ser uma região de intensa atividade biogeoquímica, onde acontece a ciclagem de nutrientes (TUFENKJI; RYAN; ELIMELECH, 2002), e de habitat e refúgio para uma série de organismos (HANNAH et al., 2009), onde a água flui através dos interstícios dos sedi- 
mentos que são predominantemente anisotrópicos (LU et al., 2012), atuando assim, como um filtro físico, químico e biológico (MUGNAl et al., 2015).

Assim, a importância do estudo da zona hiporreica reside no fato desta se caracterizar como área de intensa atividade biogeoquímica, influenciando assim, a qualidade da água de recarga do aquífero subjacente ao rio (VERAS et al., 2016).

O fluxo de água que ocorre devido à interação rio-aquífero na zona hiporreica favorece o estabelecimento de organismos, pois existe uma grande infiltração de matéria orgânica nos interstícios dos sedimentos (VERAS et al., 2017). Entre os diversos grupos de organismos que possuem o ambiente hiporreico como habitat, destaca-se a meiofauna.

Também conhecida por meiobentos, a meiofauna é o grupo de animais invertebrados que ocupa uma grande variedade de ambientes intersticiais, desde ambientes com alta salinidade até ambientes com baixa, sendo definidos metodologicamente como todos os metazoários retidos em uma peneira de $42 \mu \mathrm{m}$ e que são capazes de passar por um peneira de 500 $\mu \mathrm{m}$ (COULL, 1999).

A meiofauna tem sido bastante estudada em todo o mundo, especialmente por parte dos biólogos, que desde o início da década de 1980 têm dedicado maior atenção ao tema em questão (HARGUINTEGUY; COFRÉ; WARD, 2012). Porém estas pesquisas são muito mais concentradas em ambientes marinhos e estuarinos (MARIA; WANDENESS; ESTEVES, 2016). Em comparação a estes, a meiofauna é pouco estudada em ecossistemas de água doce, como rios e lagos (HAKENKAMP; PALMER, 2000).

No Brasil, a meiofauna é estudada desde a metade do século $X X$, a partir de pesquisas que inicialmente focalizavam na taxonomia das espécies de diferentes grupos zoológicos. Nos últimos 20 anos, as pesquisas nesta área têm se intensificado no país (MARIA, WANDENESS; ESTEVES, 2016).

A relevância da meiofauna dentro do ambiente hiporreico está na sua capacidade de facilitar a degradação da matéria orgânica. Estes organismos exercem importante tarefa na absorção de nutrientes que favorecem a eficiência natural de autopurificação na interface água subterrânea-superficial (GIERE, 2009).

A meiofauna propicia a formação de biofilmes na zona hiporreica pelo estímulo de processos microbianos que ela exerce, contribuindo para o aumento da colmatação, o que influencia a qualidade da água de recarga de um aquífero.

Por isso, a preservação da zona hiporreica, e consequentemente de sua meiofauna, é uma condição primária para o seu bom funcionamento na absorção de nutrientes (LIU et al., 2017).

Além disso, o estudo da meiofauna se apresenta como um bom indicador para os estudos sobre mudanças climáticas e impactos antropogênicos. No qual, mudanças globais podem gerar efeitos negativos, principalmente para a cadeia alimentar bentônica; e podem favorecer algumas espécies meiofau- nísticas, uma vez que podem exibir notáveis adaptações fisiológicas (GIERE, 2009; MARIA; WANDENESS; ESTEVES,2016).

Veras (2017) reitera que os ciclos de vida de pequena duração dos seres da meiofauna, que vão de 1 a 3 meses, facilitam nas observações em estudos de curto prazo.

Os regimes hidrológicos e geomorfológicos são dominantes sobre todos os outros fatores nos ecossistemas fluviais e determinam as interações e os papéis da meiofauna (HAKENKAMP; PALMER, 2000).

As variações sazonais são imprescindíveis no comportamento da fauna hiporreica. No período de alta vazão; a macrofauna possui um papel dominante e a meiofauna, um papel subordinativo, apesar de sua considerável diversidade. No período intermediário de vazão, a meiofauna ganha importância. No período da baixa vazão, os níveis de oxigênio do rio tendem a ser menores, o que força uma migração ascendente dos organismos da meiofauna para camadas mais superficiais da zona hiporreica e pode causar perdas por deriva (GIERE, 2009).

A distribuição vertical da comunidade meiofaunística nos sedimentos é controlada pela disponibilidade de oxigênio (GIERE, 2009). Palmer (1986) e Ward e Palmer (1994) explicam que a interação rio-aquífero possui influência na distribuição vertical da meiofauna. Em períodos do ano onde existe um fluxo vertical da água superficial para o aquífero, os níveis de oxigênio se elevam em zonas um pouco mais profundas, levando ao meiobentos a possibilidade de penetração para estas zonas (PALMER, 1986; WARD; PALMER, 1994).

Além disso, o efeito do hidrodinamismo também influencia a distribuição vertical, uma vez que os organismos bentônicos tendem a se proteger durante eventos de fluxo mais intenso, migrando para camadas mais profundas do leito (PALMER, 1986).

Nos períodos de cheia, o fluxo da água altera morfologicamente o leito do rio, limpando as camadas de colmatação e contribuindo para a formação de caminhos preferenciais da água para camadas mais profundas, elevando os níveis de oxigênio nestes pontos. Assim, os organismos da meiofauna podem migrar para camadas mais profundas do leito em resposta às elevações no fluxo do rio.

Diante do exposto, o presente artigo tem como objetivo contribuir com os estudos sobre a distribuição vertical da comunidade da meiofauna hiporreica em alguns pontos do rio Beberibe, levando em consideração a influência da interação rioaquífero nesta distribuição, considerando o hidrodinamismo e o fluxo vertical do rio.

\section{2. ÁREA DE ESTUDO}

O presente estudo foi realizado em trechos do rio Beberibe, entre os municípios de Recife e Olinda, em Pernambuco, no trecho correspondente ao médio curso, localizado entre a rodovia BR-101 e o seu encontro do Beberibe com o rio Morno (CAMPOS, 2003). A bacia hidrográfica do rio Beberibe (Figura 1) está inserida nos municípios de Recife (64,51\%), Olinda $(21,29 \%)$ e Camaragibe $(14,19 \%)$ e, em alguns trechos, serve 
de limite entre os municípios de Recife e Olinda. A bacia, que apresenta uma área de cerca de $81 \mathrm{~km}^{2}$, é ocupada por uma população de aproximadamente uma população de 580 mil habitantes, caracterizando uma área com alta densidade populacional de cerca de $7300 \mathrm{hab} / \mathrm{km}^{2}$ (SIRH, 2017).

Figura 1 - Mapa da bacia hidrográfica do rio Beberibe com a indicação da área de estudo

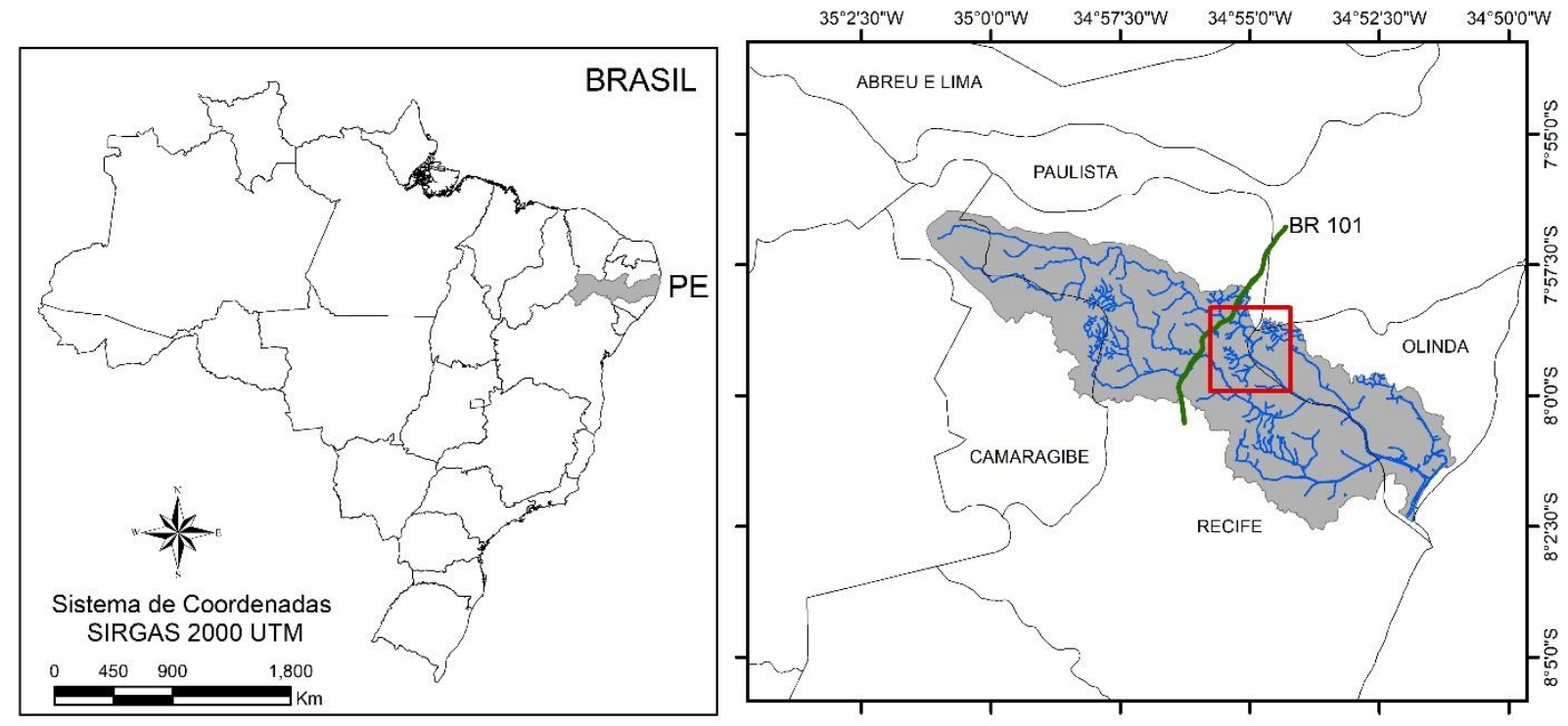

A bacia hidrográfica do rio Beberibe apresenta um ambiente com características predominantes de clima quente e úmido, com chuvas concentradas no outono e inverno. Conforme a classificação feita por Köppen, o clima dominante na região corresponde ao As" (ALVARES et al., 2013; CAMPOS, 2003).

A precipitação média anual é de aproximadamente 2450,7 $\mathrm{mm}$, sendo distribuídos em dois períodos distintos: chuvoso, de abril a agosto; e seco, de setembro a março (CAMPOS, 2003). A área da bacia apresenta uma temperatura média anual de $25,5^{\circ} \mathrm{C}$, com baixa variabilidade térmica durante o ano, mas com períodos pluviométricos bem distintos (chuvoso e seco) (INMET, 2003).

Em 2017, ano de desenvolvimento da pesquisa, o mês chuvo- so de maior índice pluviométrico foi julho com $357,4 \mathrm{~mm}$ de chuva acumulada e o mês de menor índice pluviométrico foi novembro, com 10,2 mm. 0 acumulado de precipitação pluviométrica do ano de 2017 foi de 1588,9 mm. Os dados foram obtidos na Estação Metereológica Alto da Brasileira da Agência Pernambucana de Água e Clima (APAC), o posto de monitoramento pluviométrico localizado em Recife mais próximo da área de estudo. Os valores mensais de precipitação acumulada podem ser observados na Figura 2 (APAC, 2018).

A pesquisa foi desenvolvida em 3 pontos distintos do médio curso da bacia hidrográfica do rio Beberibe (Figura 3). 0 Ponto 1 localiza-se mais a montante da bacia, o Ponto 2 é intermediário e o Ponto 3 é o mais a jusante.

Figura 2 - Precipitações médias mensais em 2017 na Estação Alto da Brasileira, Recife.

400,0
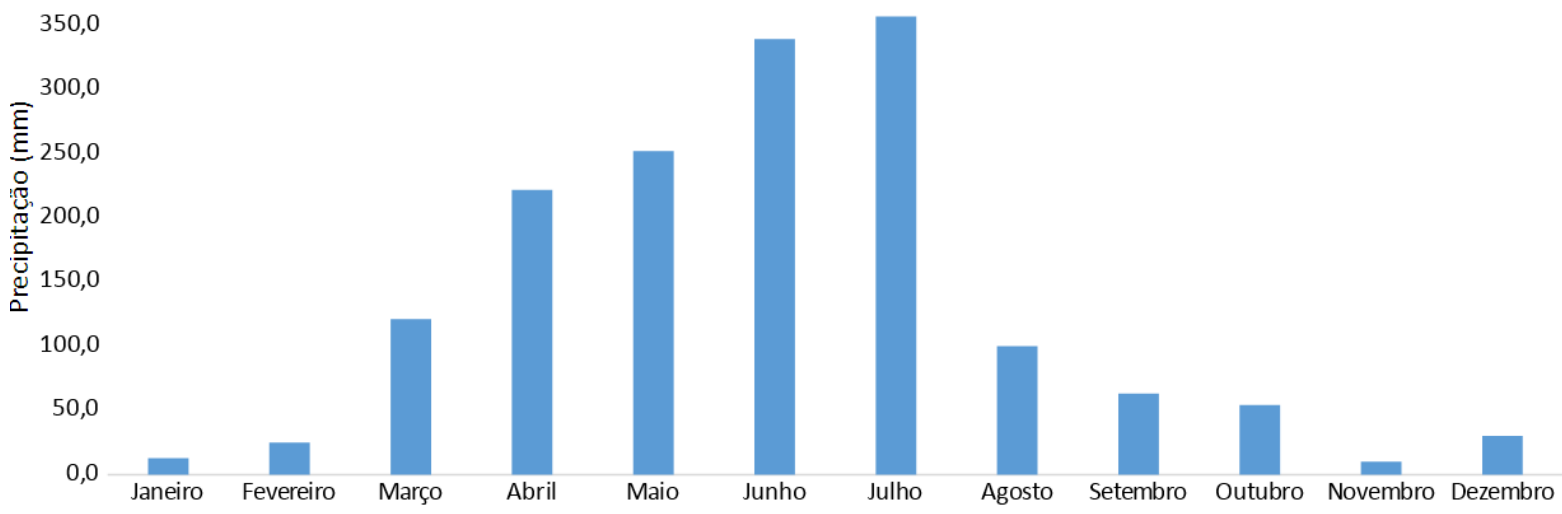

Fonte: (APAC, 2018 
Figura 3 - Localização da área de estudo e aspectos dos pontos de coleta no rio Beberibe-PE

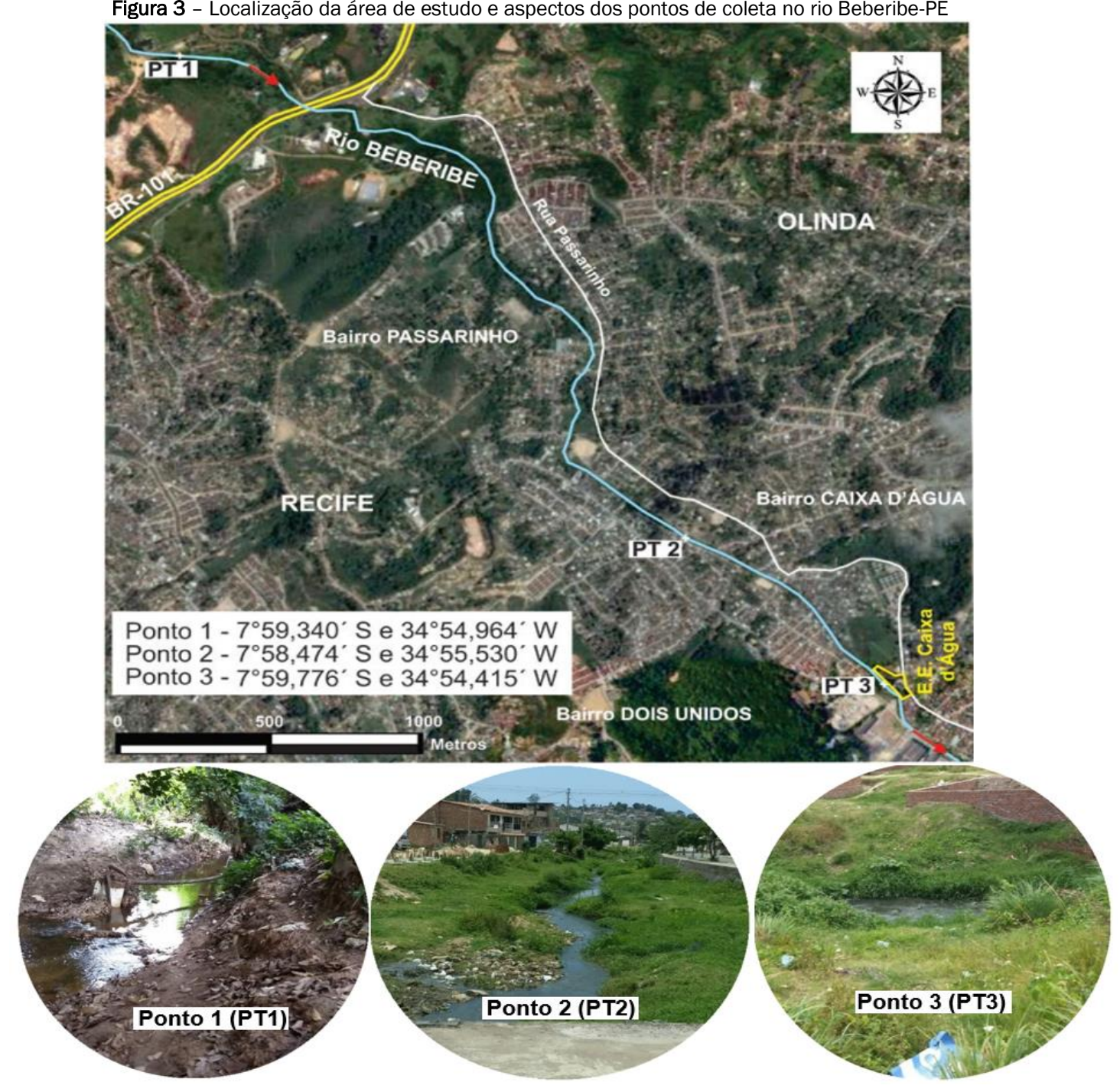

O Ponto 1 está localizado próximo e ligeiramente a montante da BR-101. Caracteriza-se por estar numa área ainda preservada do ponto de vista ambiental, com resquícios de Mata Atlântica e reservas ambientais legalmente definidas. 0 rio Beberibe não recebe, nesse trecho, grande volume de águas servidas, devido à pouca ocupação da área, e suas águas são cristalinas.

Logo após passar sob a BR-101, o rio passa a percorrer áreas de intensa urbanização, ou seja, áreas nas quais o rio possui um forte risco de sofrer degradação a partir da poluição causada por ações antrópicas.

O Ponto 2 situa-se a aproximadamente 2,7 quilômetros a jusante do Ponto 1. 0 rio Beberibe, neste ponto, apresenta um forte grau de contaminação, sendo possível observar em todo trecho tubulações de águas servidas sendo lançadas diretamente no canal fluvial.

O Ponto 3 está situado aproximadamente 800 metros a jusante do Ponto 2 e 3,5 quilômetros a jusante do Ponto 1 . Por receber uma vazão maior de esgotos domésticos, este ponto possui a aparência mais desagradável entre os pontos do es-

tudo.

Em estudo desenvolvido por Albuquerque (2015), a vazão média nos pontos 1, 2 e 3 estudados são, respectivamente, 0,12; 0,27 e $1,22 \mathrm{~m}^{3} / \mathrm{s}$.

\section{MATERIAIS E MÉTODOS}

\subsection{Diferença de carga hidráulica}

Para caracterizar o sentido do fluxo vertical entre o rio e a água subterrânea do local de estudo utilizou-se um piezômetro diferencial (Figura 4), aparelho desenvolvido na Universidade Federal de Pernambuco (UFPE) por Veras et al. (2016), baseado em Chen et al. (2008).

O equipamento é constituído de um tubo metálico com uma ponteira filtrante rosqueável na parte final, no qual fica totalmente cravada no solo permitindo a passagem de água e impedindo a passagem de grãos de solo, no interior do equipamento existe uma mangueira transparente, para facilitar a visualização do nível d'água, que vai da ponteira até a outra extremidade do equipamento (VERAS et al., 2016). 
Figura 4 - Leitura do fluxo vertical do rio com piezômetro diferencial A)Fluxo ascendente; B) Fluxo descendente; C) Sem fluxo
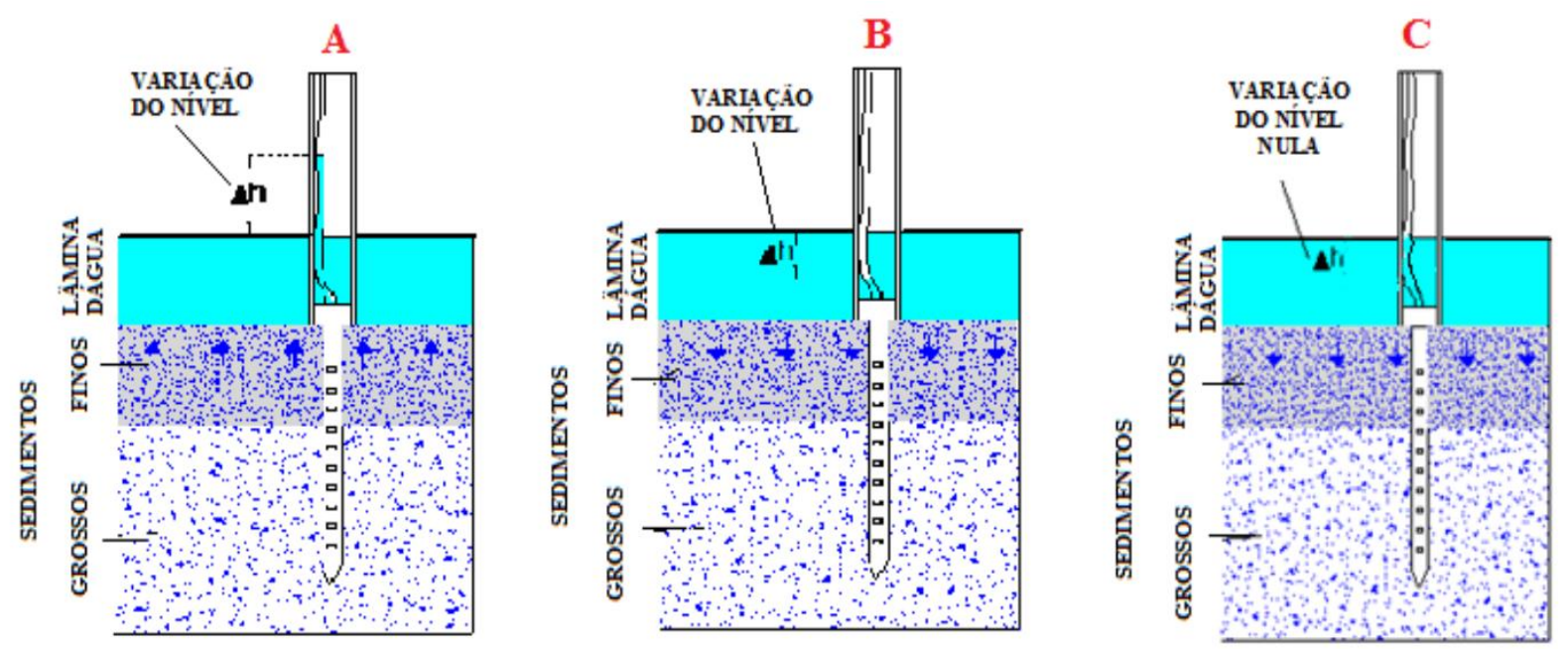

O monitoramento no campo foi realizado em três campanhas, sendo a primeira em 30/05/2017, a segunda em 04/07/2017 e a terceira em 17/10/2017 de forma a realizar medições no período chuvoso e no período seco. As leituras foram realizadas nos pontos 1,2 e 3 , e em cada ponto o piezômetro diferencial foi cravado no leito e nas duas margens do rio ao longo da seção transversal do rio, em um mesmo eixo. Os pontos 1 e 2 tem uma largura de aproximadamente $2,50 \mathrm{~m}$ e o Ponto 3 de 3,60 m, os piezômetros instalados nas margens ficaram distanciados de $0,65 \mathrm{~m}$ da borda.

As leituras das diferenças de carga hidráulica foram realizadas a cada 5 minutos até que os valores fossem estabilizados, ou atingido um tempo máximo de 35 minutos.

O monitoramento é feito com as medições do nível da lâmina d'água no rio e o nível da água no aparelho, calculando-se a diferença entre essas medições é possível saber o sentido do fluxo vertical entre o rio e o aquífero.

Existem três condições possíveis: se o nível d'água do rio estiver abaixo do nível da água observado na mangueira significa que o rio está sendo alimentado pelo aquífero neste ponto (fluxo ascendente), ou seja, o rio é classificado como efluente; se o nível da água do rio estiver acima do nível da água no instrumento pode-se concluir que o rio está alimentando o aquífero (fluxo descendente) e é classificado como influente; se ambas as medições estiverem com mesmo nível, isto caracteriza um ponto onde não existe fluxo vertical da água. Valores positivos significam que o fluxo é ascendente, enquanto que os negativos significam que o fluxo é descendente (CABRAL et al., 2001; VERAS et al., 2016).

\subsection{Meiofauna}

Foram coletadas amostras nos três pontos em meses do ano com precipitações médias distintas. As coletas se deram em abril (início do período chuvoso), julho (pico anual das precipitações médias mensais) e outubro (período seco) de 2017.

Coletou-se sedimentos do leito do rio a cada 2 centímetros a partir do topo até a profundidade de 10 centímetros. Além da amostra inicial, foram coletadas 2 réplicas, resultando em 3 amostras por ponto, totalizando 45 amostras extraídas diferentes.

A meiofauna foi amostrada conforme metodologia seguida por Veras et al. (2018), cujas etapas estão ilutradas na Figura 5. As amostras foram extraídas com amostrador cilíndrico (corer) transparente de acrílico liso com área da seção transversal de $11,33 \mathrm{~cm}^{2}$. 0 armazenamento das amostras foi feito merguIhando-as em Formaldeído a 4\% para a preservação dos organismos extraídos.

Para a realização da triagem e identificação dos organismos da meiofauna, as amostras foram levadas para o Laboratório de Dinâmica de Populações da UFPE (LABDIN) no Departamento de Zoologia do Centro de Biociências (CB).

A primeira etapa da triagem consistiu no peneiramento das amostras com peneiras geológicas de aberturas de malha de $500 \mu \mathrm{m}, 300 \mu \mathrm{m}, 200 \mu \mathrm{m}, 100 \mu \mathrm{m}$ e $45 \mu \mathrm{m}$. Assim, ocorreu a separação da meiofauna, pois o material que é retido na peneira de $500 \mu \mathrm{m}$ (macrofauna) e o que passa pela peneira de $45 \mu \mathrm{m}$ (microfauna) foram descartados (VERAS et al., 2018).

Posteriormente, o material retido em cada peneira foi armazenado em novos recipientes plásticos. Desta maneira, cada amostra armazenada inicialmente se divide em 4 novos recipientes referente à cada uma das peneiras $(300 \mu \mathrm{m}, 200 \mu \mathrm{m}$, $100 \mu \mathrm{m}$ e $45 \mu \mathrm{m})$.

A estas amostras separadas por peneiras, foi adicionado corante rosa-de-bengala diluído em formol, onde deixou agir por no mínimo 24 horas, para facilitar o processo de triagem e identificação dos mesmos.

A identificação foi feita a nível de grandes grupos taxonômicos. As amostras, depois de devidamente coradas, são colocadas na Placa de Dollfus para a realização da triagem com o auxílio de uma Lupa com $4 x$ de aumento. Assim, a identificação foi realizada minuciosamente e, conforme era feita, as quantidades de indivíduos encontrados eram computados em planilha separados por ponto de coleta, grupo taxonômico e profundidade. 
Figura 5 - Etapas de amostragem e quantificação dos indivíduos da meiofauna A) Extração dos sedimentos hiporreicos até $10 \mathrm{~cm}$ de profundidade B) Armazenamento das amostras a cada $2 \mathrm{~cm}$; C) Peneiramento das amostras; D) Processo de identificação e quantificação dos meiobentos
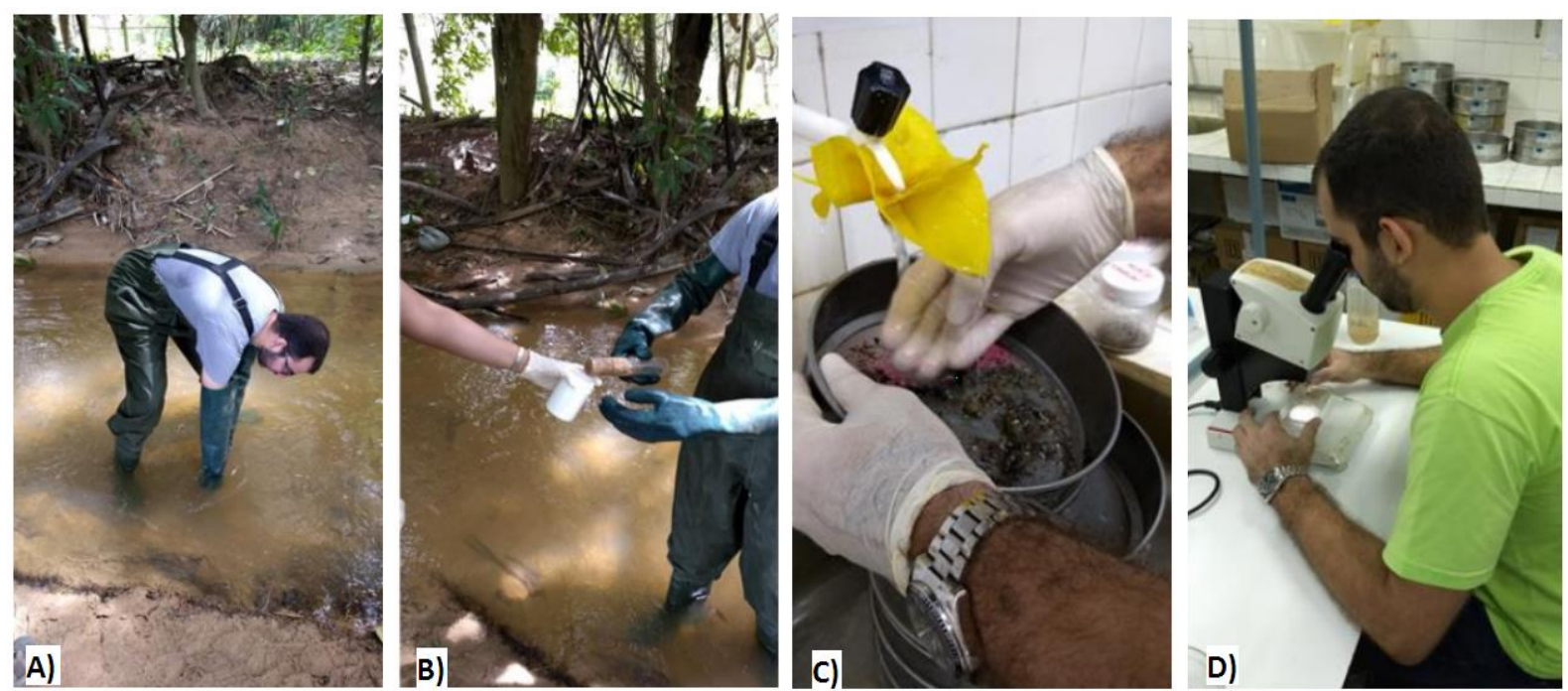

\section{RESULTADOS}

\subsection{Medição da diferença da carga hidráulica}

A Figura 6 apresenta as precipitações acumuladas diárias no período de medição a partir dos dados pluviométricos da Estação Alto da Brasileira.

Na primeira medição de campo três precipitações entre 20 e
$35 \mathrm{~mm}$ ocorreram cerca de 3 a 4 semanas antes, e foi registrado uma precipitação acima de $40 \mathrm{~mm}$ no dia anterior a medição. Já na segunda coleta, 7 precipitações acima de $25 \mathrm{~mm}$ ocorreram nos 30 dias anteriores, sendo 4 delas na semana anterior, uma delas chegou a $70 \mathrm{~mm}$ quatro dias antes. $\mathrm{Na}$ última medição do gradiente hidráulico a maior precipitação chegou a 3,90 mm e a última precipitação ocorreu 11 dias antes, como pode ser observado na Figura 6.

Figura 6 - Gráfico da precipitação na Estação Alto da Brasileira no período de 01/05/2017 a 17/10/2017

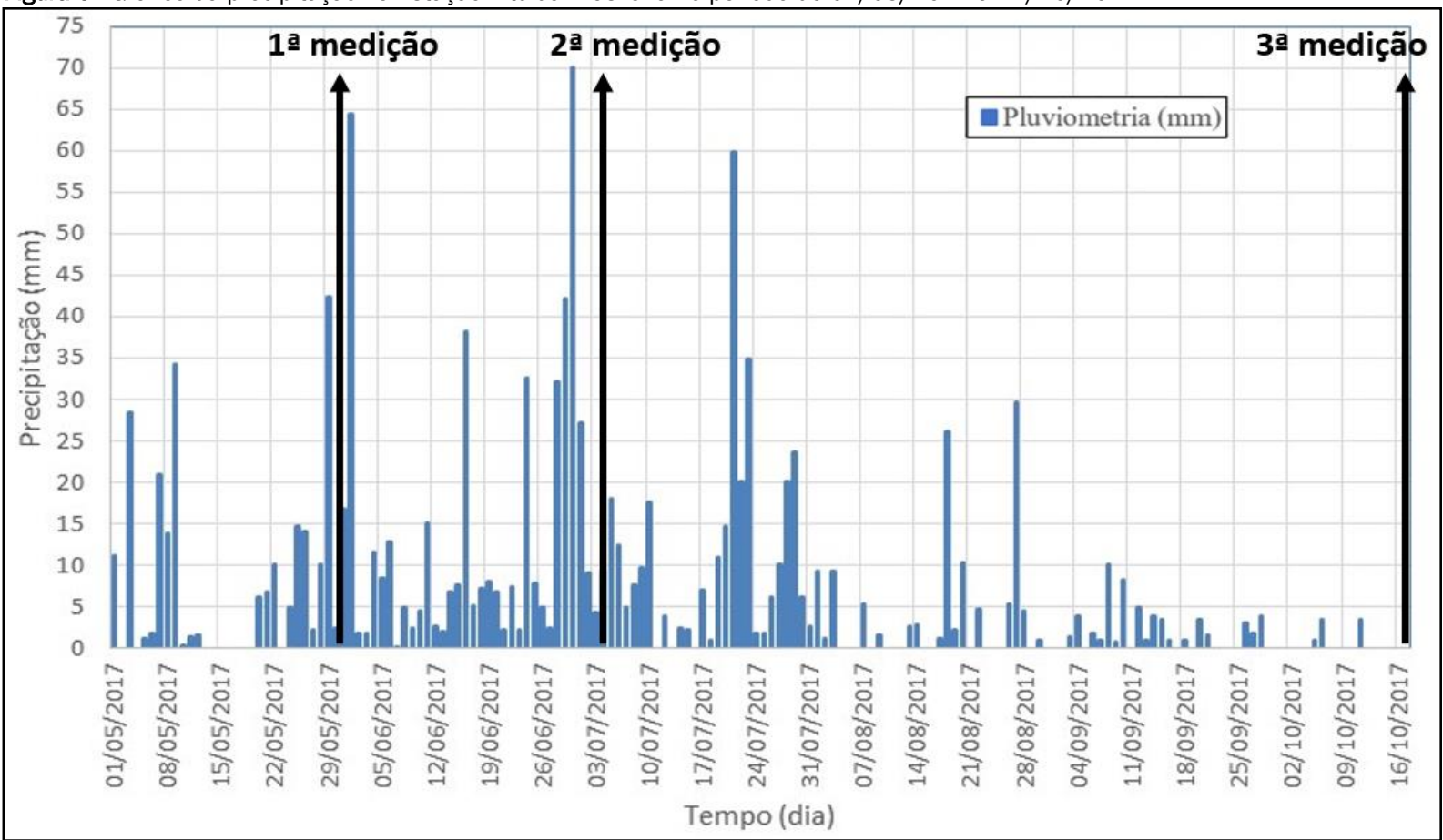


As Figuras 7, 8 e 9 apresentam as variações temporais da diferença de carga hidráulica entre o rio e o aquífero nos Pontos 1, 2 e 3, respectivamente. A identificação de cada medição é dada pela seguinte nomenclatura: Ponto 1, 2 ou 3 (P1, P2 e $\mathrm{P3}$ ); margem esquerda, centro ou margem direita (ME, C e MD); e o dia da coleta que ocorreu em 2017 (30/05, 04/07 e 17/10). Deste modo, por exemplo, a medição P2MD30/05 refere-se à realizada no ponto 2 , na margem direita do rio, no dia 30 de maio de 2017.

O Ponto 1 apresenta pouca carga de poluentes se comparado com os outros pontos, por isso, é possível que a colmatação do leito se deve ao acúmulo de sedimentos finos e não da matéria orgânica de origem antrópica.
Nas duas primeiras medições neste ponto, houve precipitações relativamente de maior magnitude poucos dias antes (43 $\mathrm{mm}$ e $70 \mathrm{~mm}$, respectivamente), o que provavelmente gerou uma vazão maior no rio que limpou a camada de colmatação, aumentando a condutividade hidráulica do leito, elevando a carga hidráulica do rio e favorecendo o fluxo descendente, mesmo que este tenha sido de pequena magnitude, como pode ser visto na Figura 7.

Já na terceira medição, que foi no período de estiagem, houve uma rápida estabilização próximo a zero, indicando pequeno fluxo vertical na interação rio-aquífero.

Figura 7 - Variação temporal da diferença de carga hidráulica entre rio e aquífero subjacente no Ponto 1

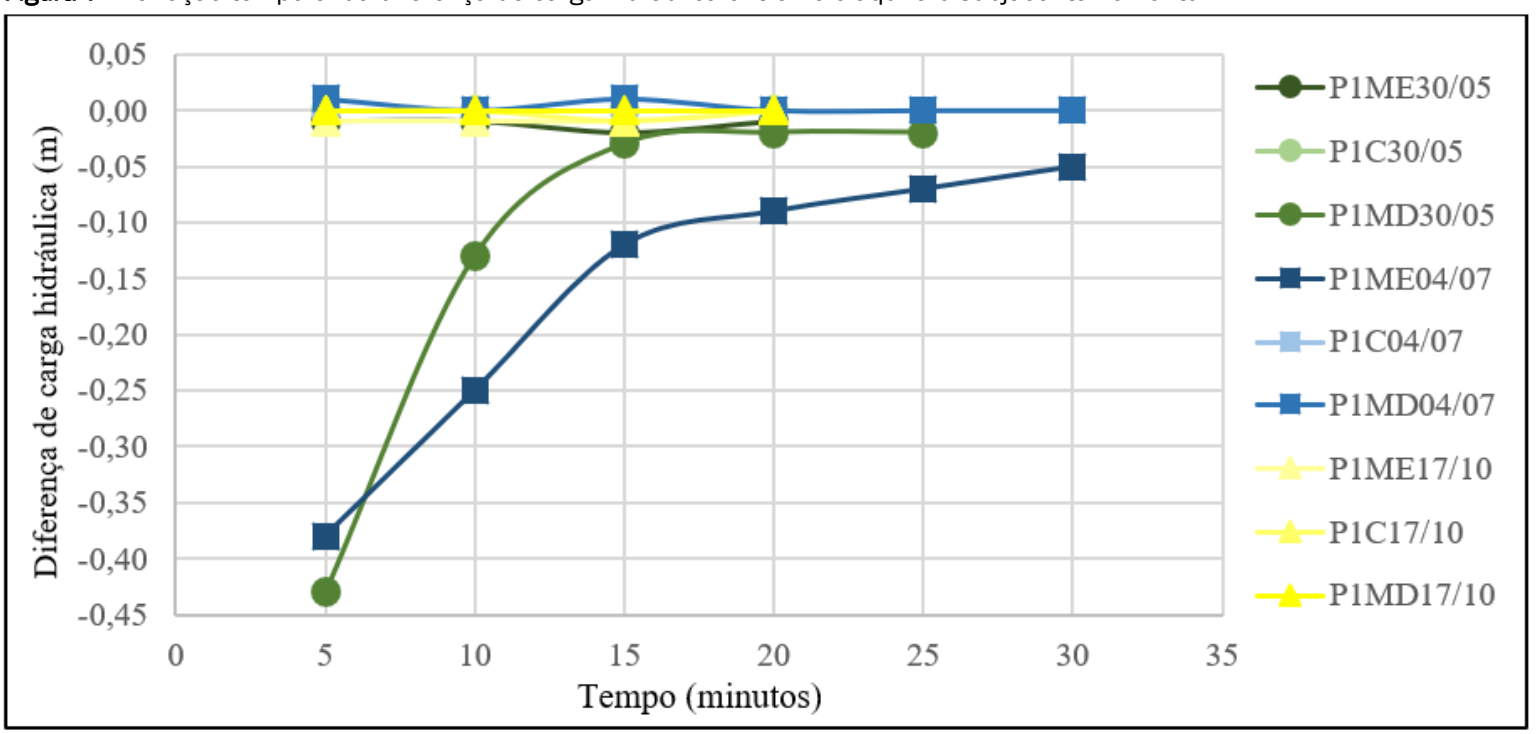

No Ponto 2 de forma geral as medições se estabilizaram rapidamente se aproximando de zero, exceto nas margens da primeira coleta, em que a margem direita não estabilizou passa dos 35 minutos e a margem esquerda estabiliza-se com valor positivo, indicando fluxo ascendente (Figura 8).

Figura 8 - Variação temporal da diferença de carga hidráulica entre rio e aquífero subjacente no Ponto 2

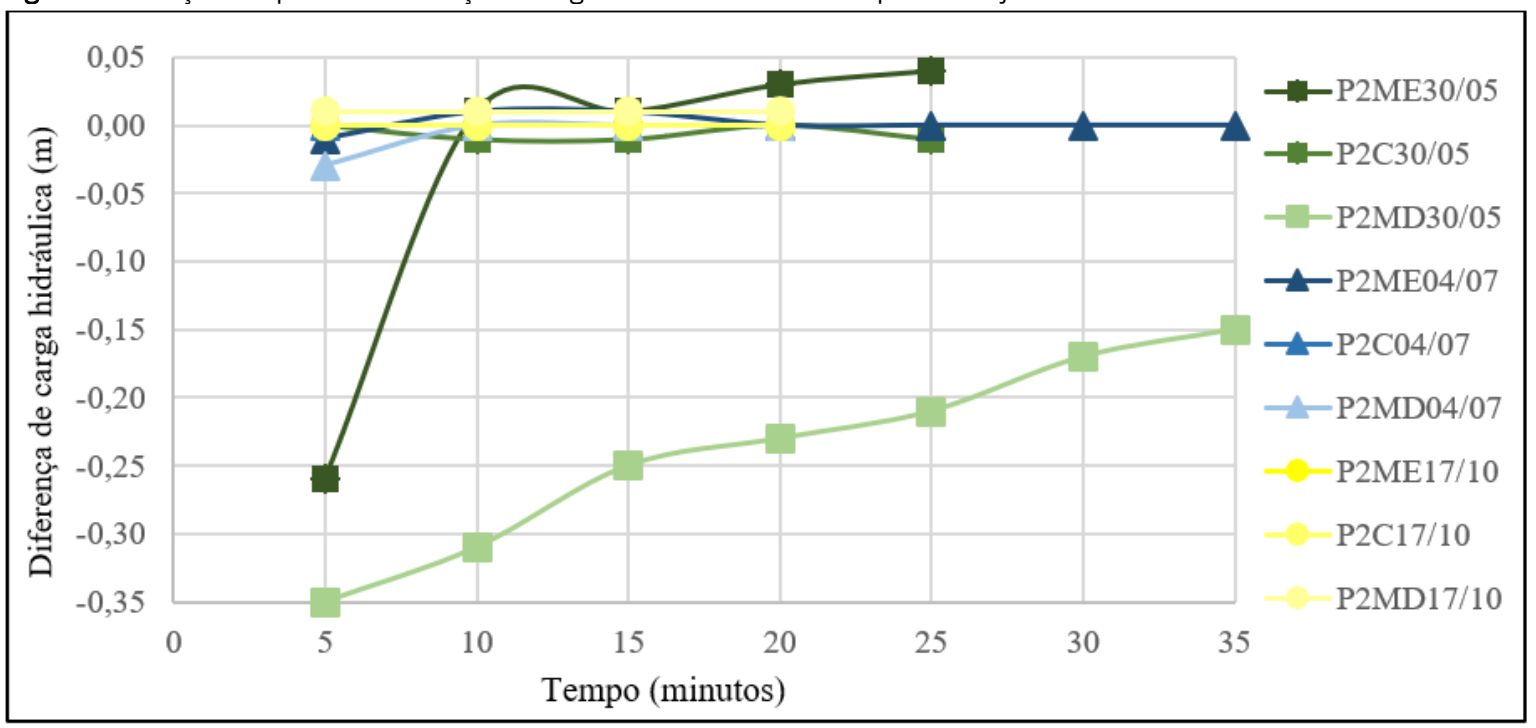


No Ponto 3, foi observado em campo a presença de finos nas margens, dificultando a cravação do equipamento. Este tipo de sedimentos podem estar relacionados à grande quantidade de matéria orgânica proveniente da poluição de origem antrópica (BARCELLOS et al., 2016). Este fator granulométrico retardou a estabilização da margem esquerda na primeira medição, indicando fluxo descendente de pequena magnitude nesta medição, como pode ser visto na Figura 9. Nas outras medições, observou-se o fluxo vertical nulo.

Figura 9 - Variação temporal da diferença de carga hidráulica entre rio e aquífero subjacente no Ponto 3.

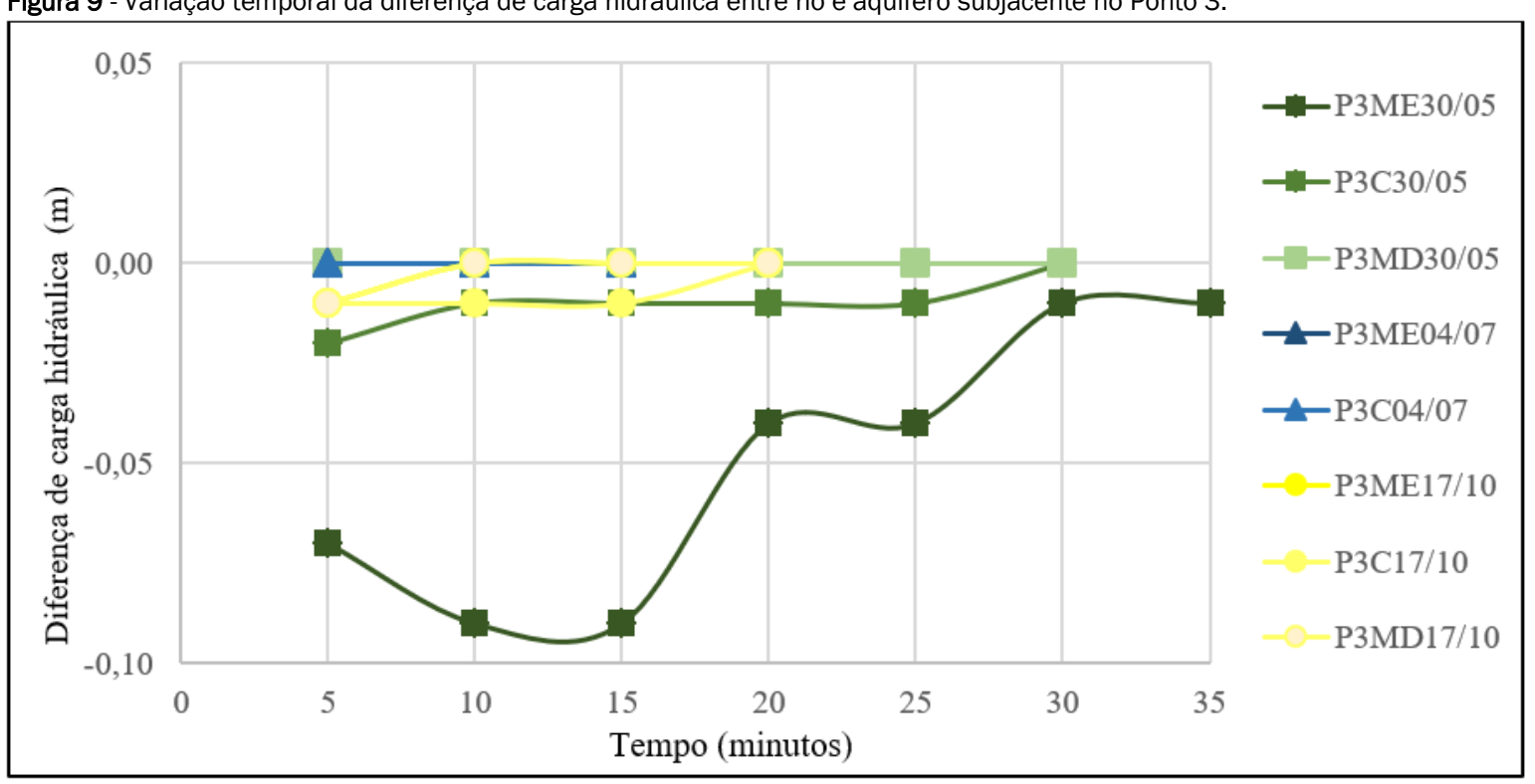

Os três pontos tiveram resultados parecidos, mostrando uma estabilização aos 20 minutos de atividade, com valores negativos próximos de zero, indicando pouca interação rio-aquífero e fluxo descendente.

Todas as medições realizadas em outubro (estação seca) indicaram fluxo nulo, muito provavelmente devido a não existência de precipitações que fossem capazes de limpar a camada superficial comaltada do leito. Apenas houve fluxo ascendente no período de chuva na margem esquerda do ponto 2 durante a primeira coleta.

Este resultado apresentou dados um pouco diferentes dos observados por Veras et al. (2016), ao realizar pesquisas no mesmo trecho do rio Beberibe no ano de 2014. No estudo de Veras et al. (2016) o período chuvoso também foi responsável predominantemente por fluxo descendente, com a diferença de que no período seco foi observado uma maior intensidade no fluxo descendente. Isto indica que houve alterações na composição sedimentológica da zona hiporreica do rio neste intervalo de tempo entre estas das pesquisas.

\subsection{Meiofauna}

Ao total foram contabilizados 4906 indivíduos da meiofauna pertencentes a 8 grupos taxonômicos: Nematoda, Annelida, Rotifera, Ostracoda, Insecta, Anfipoda, Copepoda e Acari. Os grupos que apresentaram maior abundância foram Nematoda, Annelida e Rotifera, sobretudo os dois primeiros.

0 ponto que apresentou uma quantidade mais abundante em meiofauna foi o ponto 3 com 2796 indivíduos; seguido pelo ponto 1 , com 1118 indivíduos e pelo ponto 2, com 992.
Foi possível calcular a abundância média de cada grupo taxonômico e o seu desvio-padrão para os dados obtidos em cada profundidade. É importante salientar que os valores de abundância média da meiofauna podem ser representados por números decimais, uma vez que eles são resultados da média da abundância. Estes valores podem ser vistos nas Tabelas 1,2 e 3.

A tabela 1 refere-se à abundância média no ponto 1 por grupo taxonômico em cada profundidade nos meses estudados. Percebe-se que os grupos rotífera e outros tiveram poucos indivíduos, mas que se concentraram principalmente nas amostras de abril. Além disso, abril foi o mês que apresentou o maior desvio padrão entre as amostras, sobretudo na profundidade 4-6 cm.

A Figura 10 apresenta as abundâncias médias no ponto 1 de cada um dos grupos taxonômicos em forma de perfil. Observase que em julho e em outubro a camada mais superficial da zona hiporreica foi a que apresentou um número maior do que as demais. Esta é uma condição natural na distribuição vertical de organismos hiporreicos devido à maior disponibilidade de oxigênio nas camadas mais superficiais e o decréscimo desta disponibilidade com a profundidade.

Percebe-se, no entanto, que em abril, o mês com maior abundância observada mo ponto 1 , teve a profundidade $4-6 \mathrm{~cm}$ como a mais abundante entre as outras profundidades. Esta situação pode ter ocorrido em consequência ao fluxo descendente, como foi observado na medição que ocorreu em maio neste ponto, levando a um maior número de indivíduos nesta profundidade pertencentes a todos os grupos taxonômicos estudados. 
Tabela 1 - Abundância média (indivíduos) e desvio-padrão dos grandes grupos encontrados no ponto 1

NEMATODA

ANNELIDA

ROTIFERA

OUTROS

\begin{tabular}{|c|c|c|c|c|c|c|c|c|c|}
\hline \multicolumn{2}{|c|}{ AMOSTRAS } & \multirow{2}{*}{$\begin{array}{c}\text { Abund. } \\
\text { média }\end{array}$} & \multirow{2}{*}{$\begin{array}{c}\mathrm{DP} \\
32,1\end{array}$} & \multirow{2}{*}{$\begin{array}{c}\text { Abund. } \\
\text { média }\end{array}$} & \multirow{2}{*}{$\begin{array}{c}\text { DP } \\
13,5\end{array}$} & \multirow{2}{*}{$\begin{array}{c}\text { Abund. } \\
\text { média }\end{array}$} & \multirow{2}{*}{$\begin{array}{c}\text { DP } \\
8,1\end{array}$} & \multirow{2}{*}{$\begin{array}{c}\begin{array}{c}\text { Abund. } \\
\text { média }\end{array} \\
7,0\end{array}$} & \multirow{2}{*}{$\begin{array}{l}\text { DP } \\
6,2\end{array}$} \\
\hline \multirow{5}{*}{ 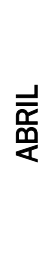 } & $0-2 \mathrm{~cm}$ & & & & & & & & \\
\hline & $2-4 \mathrm{~cm}$ & 10,7 & 3,8 & 14,7 & 4,9 & 4,0 & 6,9 & 3,3 & 5,8 \\
\hline & $4-6 \mathrm{~cm}$ & 43,0 & 50,3 & 24,0 & 24,2 & 6,7 & 11,5 & 12,0 & 20,8 \\
\hline & $6-8 \mathrm{~cm}$ & 5,3 & 2,1 & 9,3 & 4,6 & 0,0 & 0,0 & 1,7 & 2,1 \\
\hline & $8-10 \mathrm{~cm}$ & 4,3 & 1,5 & 8,0 & 4,4 & 0,3 & 0,6 & 1,7 & 1,2 \\
\hline \multirow{5}{*}{$\begin{array}{l}\text { 우 } \\
\text { 극 }\end{array}$} & $0-2 \mathrm{~cm}$ & 22,7 & 13,7 & 21,0 & 11,3 & 0,3 & 0,6 & 0,0 & 0,0 \\
\hline & $2-4 \mathrm{~cm}$ & 4,7 & 4,0 & 8,3 & 7,2 & 0,3 & 0,6 & 0,3 & 0,6 \\
\hline & $4-6 \mathrm{~cm}$ & 4,3 & 4,5 & 2,7 & 2,5 & 0,0 & 0,0 & 0,0 & 0,0 \\
\hline & $6-8 \mathrm{~cm}$ & 3,3 & 2,3 & 8,7 & 6,5 & 0,0 & 0,0 & 0,0 & 0,0 \\
\hline & $8-10 \mathrm{~cm}$ & 6,0 & 5,3 & 3,3 & 4,9 & 0,0 & 0,0 & 0,0 & 0,0 \\
\hline \multirow{5}{*}{$\begin{array}{l}\text { 웅 } \\
\text { 号 } \\
\text { 응 }\end{array}$} & $0-2 \mathrm{~cm}$ & 7,7 & 7,1 & 12,0 & 13,7 & 0,0 & 0,0 & 0,0 & 0,0 \\
\hline & $2-4 \mathrm{~cm}$ & 2,3 & 4,0 & 10,0 & 9,0 & 0,0 & 0,0 & 0,0 & 0,0 \\
\hline & $4-6 \mathrm{~cm}$ & 3,7 & 4,6 & 8,0 & 7,0 & 0,3 & 0,6 & 0,7 & 1,2 \\
\hline & $6-8 \mathrm{~cm}$ & 1,0 & 1,0 & 3,3 & 2,5 & 0,0 & 0,0 & 0,0 & 0,0 \\
\hline & $8-10 \mathrm{~cm}$ & 4,0 & 4,6 & 4,3 & 1,2 & 0,0 & 0,0 & 0,3 & 0,6 \\
\hline
\end{tabular}

$\mathrm{DP}=$ desvio padrão

Figura 10 - Perfis de abundância média da meiofauna por profundidade no Ponto 1

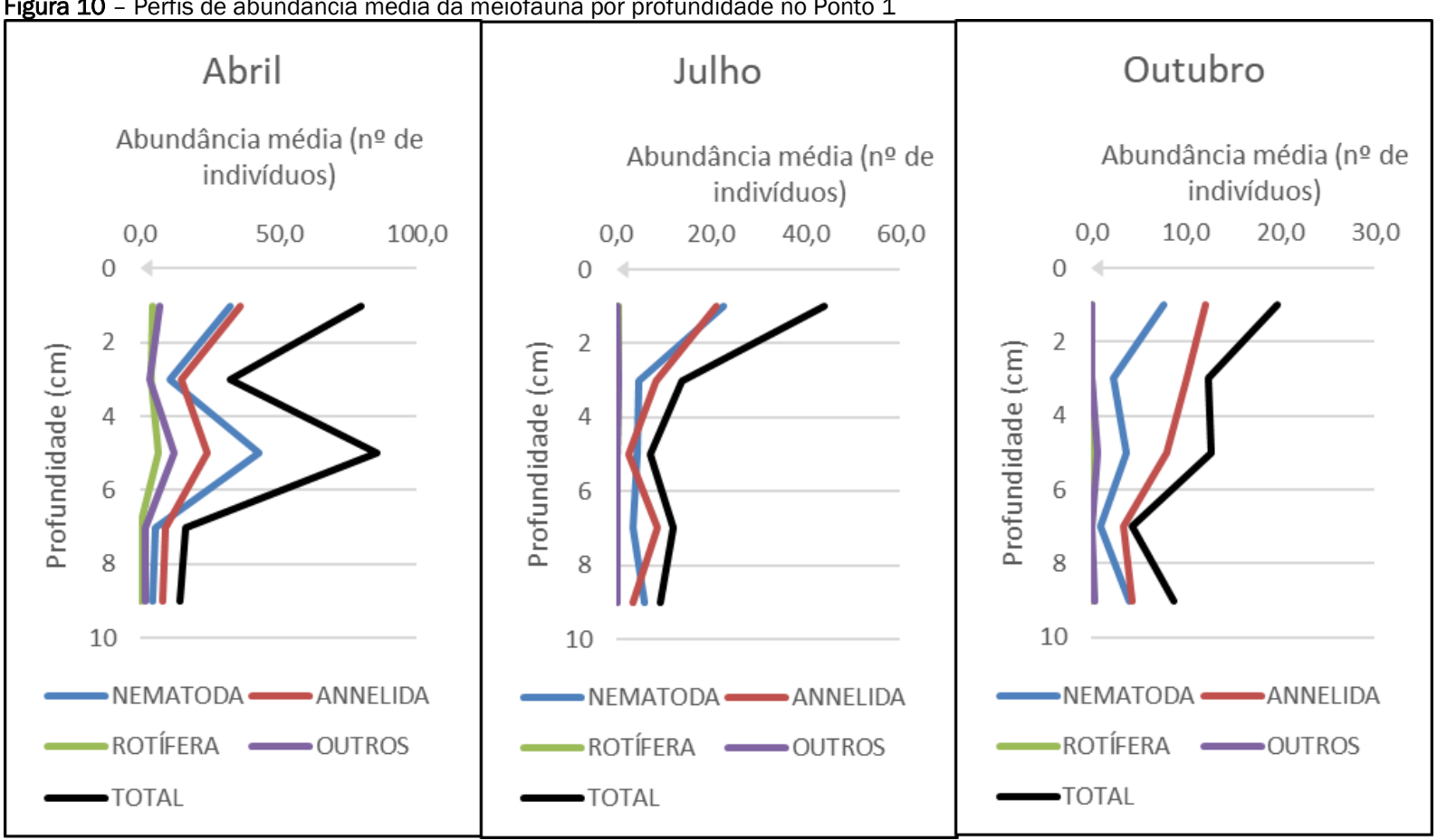

É notável que apesar do mês de julho ter sido o mais chuvoso e consequentemente o de maior vazão do rio, este hidrodinamismo não influenciou na migração dos organismos da meiofauna para camadas inferiores.
A tabela 2 apresenta as amostras do ponto 2 que não tiveram um desvio-padrão tão elevado comparado ao ponto 1. A partir desta tabela e da Figura 11 é possível observar que no mês de abril, em média, a quantidade de indivíduos foi diminuindo gradativamente à medida que ficava mais profundo. 
Tabela 2 - Abundância média (indivíduos) e desvio-padrão dos grandes grupos encontrados no ponto 2

\begin{tabular}{|c|c|c|c|c|c|c|c|c|c|}
\hline \multirow{2}{*}{\multicolumn{2}{|c|}{ AMOSTRAS }} & \multicolumn{2}{|c|}{ NEMATODA } & \multicolumn{2}{|c|}{ ANNELIDA } & \multicolumn{2}{|c|}{ ROTIFERA } & \multicolumn{2}{|c|}{ OUTROS } \\
\hline & & $\begin{array}{l}\text { Abund. } \\
\text { média }\end{array}$ & DP & $\begin{array}{l}\text { Abund. } \\
\text { méd. }\end{array}$ & DP & $\begin{array}{l}\text { Abund. } \\
\text { média }\end{array}$ & DP & $\begin{array}{l}\text { Abund. } \\
\text { média }\end{array}$ & DP \\
\hline \multirow{5}{*}{$\begin{array}{c}\overrightarrow{\bar{\alpha}} \\
\stackrel{\underline{q}}{\alpha}\end{array}$} & $0-2 \mathrm{~cm}$ & 7,7 & 4,7 & 5,0 & 3,6 & 1,3 & 2,3 & 1,3 & 0,6 \\
\hline & $2-4 \mathrm{~cm}$ & 5,7 & 2,9 & 1,7 & 0,6 & 0,0 & 0,0 & 1,0 & 1,7 \\
\hline & $4-6 \mathrm{~cm}$ & 4,0 & 2,6 & 1,7 & 0,6 & 0,0 & 0,0 & 0,7 & 0,6 \\
\hline & $6-8 \mathrm{~cm}$ & 2,3 & 2,1 & 2,3 & 1,2 & 0,0 & 0,0 & 0,3 & 0,6 \\
\hline & $8-10 \mathrm{~cm}$ & 3,0 & 2,6 & 1,0 & 1,0 & 0,0 & 0,0 & 0,0 & 0,0 \\
\hline \multirow{5}{*}{$\begin{array}{l}\text { 우 } \\
\text { 곡 }\end{array}$} & $0-2 \mathrm{~cm}$ & 22,7 & 17,0 & 38,0 & 15,1 & 0,3 & 0,6 & 0,0 & 0,0 \\
\hline & $2-4 \mathrm{~cm}$ & 5,7 & 4,0 & 10,0 & 5,0 & 0,0 & 0,0 & 0,0 & 0,0 \\
\hline & $4-6 \mathrm{~cm}$ & 8,3 & 7,5 & 25,3 & 11,0 & 1,0 & 1,7 & 0,0 & 0,0 \\
\hline & $6-8 \mathrm{~cm}$ & 3,0 & 1,7 & 11,0 & 8,7 & 0,0 & 0,0 & 0,0 & 0,0 \\
\hline & $8-10 \mathrm{~cm}$ & 6,0 & 5,6 & 11,0 & 8,9 & 0,3 & 0,6 & 0,0 & 0,0 \\
\hline \multirow{5}{*}{ 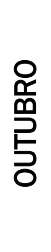 } & $0-2 \mathrm{~cm}$ & 22,7 & 10,0 & 18,3 & 10,3 & 0,0 & 0,0 & 0,3 & 0,6 \\
\hline & $2-4 \mathrm{~cm}$ & 37,7 & 23,2 & 16,3 & 13,1 & 0,3 & 0,6 & 0,7 & 1,2 \\
\hline & $4-6 \mathrm{~cm}$ & 9,0 & 3,0 & 7,0 & 6,2 & 0,3 & 0,6 & 0,7 & 1,2 \\
\hline & $6-8 \mathrm{~cm}$ & 7,0 & 2,0 & 7,7 & 4,7 & 0,0 & 0,0 & 0,3 & 0,6 \\
\hline & $8-10 \mathrm{~cm}$ & 15,0 & 9,8 & 5,7 & 2,1 & 0,0 & 0,0 & 0,0 & 0,0 \\
\hline
\end{tabular}

$\mathrm{DP}=$ desvio padrão

Nos meses de julho e outubro, foram observadas mudanças nesse comportamento. Apesar das maiores concentrações de meiofauna tenham sido encontradas nas menores profundidades, ou seja, nas camadas mais superficiais, a diminuição não se deu gradativamente com a profundidade. Isto é diferente do esperado, uma vez que a concentração de oxigênio dissolvido na zona hiporreica decai gradualmente com a profundidade (REEDER et al., 2018).

Em julho, a maior abundância se deu na profundidade $0-2 \mathrm{~cm}$ com média de 34,7 indivíduos, a segunda maior abundância ocorreu na profundidade $4-6 \mathrm{~cm}$ com 34,7 indivíduos. As profundidades $2-4 \mathrm{~cm}, 6-8 \mathrm{~cm}$ e $8-10 \mathrm{~cm}$ tiveram abundâncias médias de 15,7; 14 e 17,3; respectivamente. Mostrando que houve um acréscimo entre as profundidades $2-4 \mathrm{~cm}$ e $4-6 \mathrm{~cm}$, facilmente identificado na Figura 11.
0 mês de outubro foi o único momento no qual, no ponto de pesquisa 2, a maior abundância de meiofauna não foi registrada na camada superficial. De fato, na profundidade $0-2 \mathrm{~cm}$ foi encontrado um grande número de meiobentos em média $(41,3)$, porém a profundidade $2-4 \mathrm{~cm}$ foi a mais abundante em meiofauna com 55 indivíduos. As profundidades 4-6 cm, 6-8 $\mathrm{cm}$ e $8-10 \mathrm{~cm}$ contabilizaram em média, respectivamente, 17 , 15 e 20,7 indivíduos.

Através da Tabela 3, pode-se observar que em julho o ponto 3 apresentou desvios-padrão bem elevados referentes aos valores de nematodas e principalmente de annelidas. Esta observação é esperada, tendo em vista que o ponto 3 contabilizou uma enorme quantidade de meiobentos em julho. Assim, era de se esperar valores consideráveis de desvio-padrão. 
Figura 11 - Perfis de abundância média da meiofauna por profundidade no Ponto 2

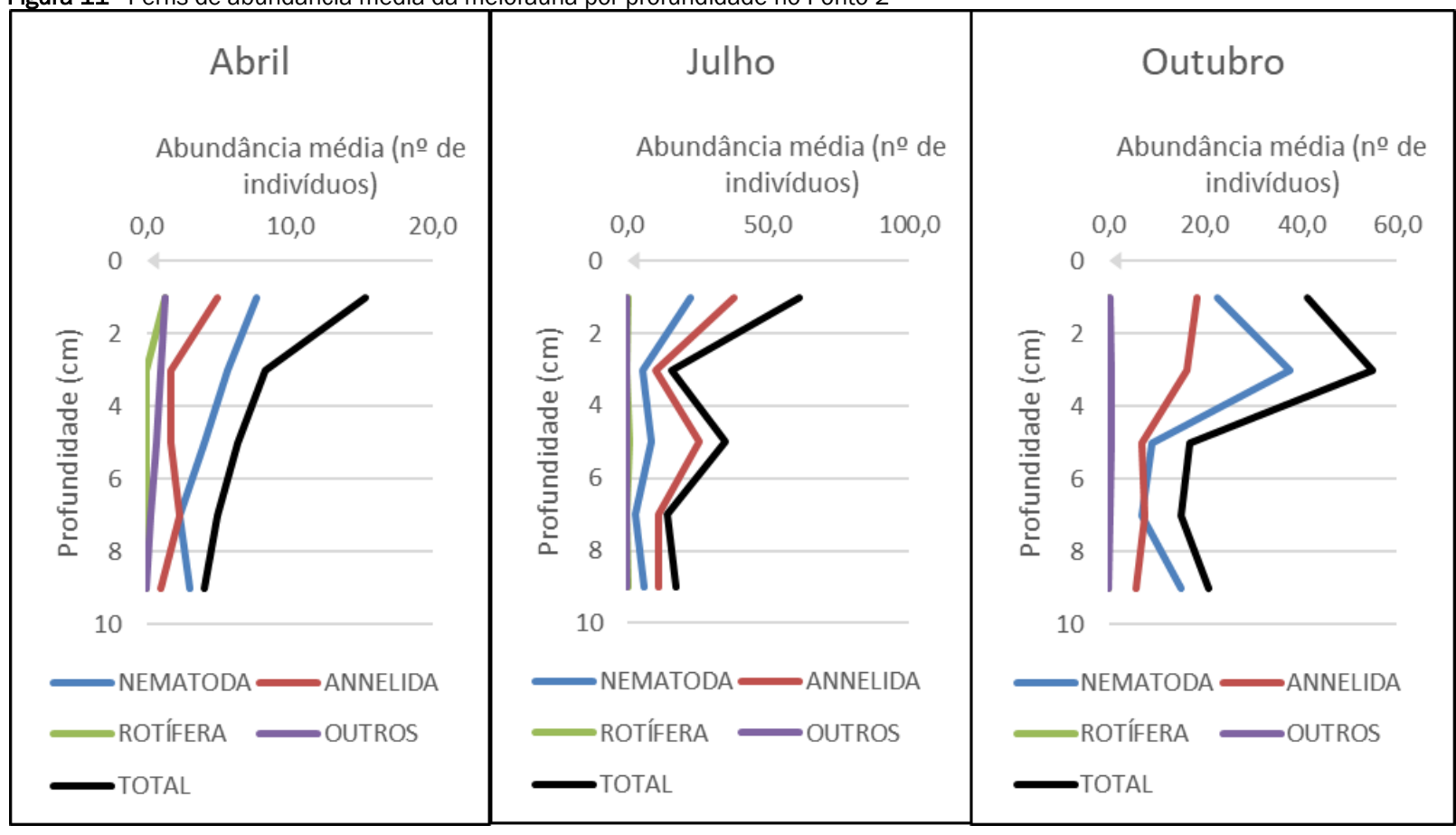

Tabela 3 - Abundância média (indivíduos) e desvio-padrão dos grandes grupos encontrados no ponto 3

\begin{tabular}{|c|c|c|c|c|c|c|c|c|c|}
\hline \multirow{2}{*}{\multicolumn{2}{|c|}{ AMOSTRAS }} & \multicolumn{2}{|c|}{ NEMATODA } & \multicolumn{2}{|c|}{ ANNELIDA } & \multicolumn{2}{|c|}{ ROTIFERA } & \multicolumn{2}{|c|}{ OUTROS } \\
\hline & & $\begin{array}{c}\text { Abund. mé- } \\
\text { dia }\end{array}$ & DP & Abund. média & DP & Abund. média & DP & Abund. média & $\mathrm{DP}$ \\
\hline \multirow{5}{*}{ 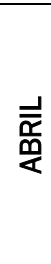 } & $0-2 \mathrm{~cm}$ & 42,0 & 21,4 & 30,7 & 14,2 & 0,0 & 0,0 & 0,7 & 1,2 \\
\hline & $2-4 \mathrm{~cm}$ & 26,0 & 24,0 & 15,3 & 2,5 & 0,0 & 0,0 & 0,0 & 0,0 \\
\hline & $4-6 \mathrm{~cm}$ & 10,7 & 8,3 & 7,0 & 0,0 & 0,0 & 0,0 & 1,7 & 2,1 \\
\hline & $6-8 \mathrm{~cm}$ & 8,7 & 2,9 & 5,0 & 3,0 & 0,0 & 0,0 & 0,3 & 0,6 \\
\hline & $8-10 \mathrm{~cm}$ & 4,3 & 2,5 & 5,3 & 3,2 & 0,0 & 0,0 & 0,3 & 0,6 \\
\hline \multirow{5}{*}{ 우 } & $0-2 \mathrm{~cm}$ & 47,7 & 39,3 & 89,0 & 68,8 & 0,7 & 0,6 & 3,7 & 3,8 \\
\hline & $2-4 \mathrm{~cm}$ & 74,3 & 61,7 & 128,0 & 89,4 & 0,0 & 0,0 & 6,0 & 6,6 \\
\hline & $4-6 \mathrm{~cm}$ & 49,7 & 22,7 & 137,0 & 54,8 & 0,0 & 0,0 & 1,7 & 2,9 \\
\hline & $6-8 \mathrm{~cm}$ & 12,3 & 12,0 & 41,0 & 24,0 & 0,0 & 0,0 & 0,0 & 0,0 \\
\hline & $8-10 \mathrm{~cm}$ & 12,3 & 11,1 & 44,7 & 37,1 & 0,0 & 0,0 & 0,0 & 0,0 \\
\hline \multirow{5}{*}{ 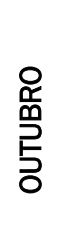 } & $0-2 \mathrm{~cm}$ & 17,7 & 18,1 & 7,0 & 8,7 & 0,7 & 1,2 & 1,7 & 2,9 \\
\hline & $2-4 \mathrm{~cm}$ & 20,3 & 6,4 & 14,7 & 12,0 & 1,0 & 1,0 & 1,7 & 2,1 \\
\hline & $4-6 \mathrm{~cm}$ & 11,0 & 8,5 & 14,0 & 9,6 & 1,0 & 1,0 & 2,7 & 4,6 \\
\hline & $6-8 \mathrm{~cm}$ & 12,7 & 11,6 & 12,0 & 12,3 & 1,0 & 1,7 & 0,7 & 1,2 \\
\hline & $8-10 \mathrm{~cm}$ & 3,3 & 2,9 & 3,0 & 3,0 & 0,0 & 0,0 & 0,0 & 0,0 \\
\hline
\end{tabular}

$\mathrm{DP}=$ desvio padrão

A Figura 12 apresenta os perfis de abundância média no ponto 3. Em abril, observa-se uma diminuição gradativa da abundância com a profundidade. A abundância média da camada mais superficial até a mais profunda foi, respectivamente, 73,3; 41,3; 19,3; 14 e 10.

Em julho, o ponto 3 apresentou os maiores valores de abundância entre todos os pontos e todos os meses. As maiores abundâncias ocorreram nos $6 \mathrm{~cm}$ superficiais, sendo a camada de $2-4 \mathrm{~cm}$ a que teve o maior número de indivíduos $(208,3)$. A profundidade $4-6 \mathrm{~cm}$ foi a segunda mais numerosa com 188,3; seguida da profundidade $0-2 \mathrm{~cm}$ com 141 indivíduos. As profundidades $6-8 \mathrm{~cm}$ e $8-10 \mathrm{~cm}$ tiveram em média, respectivamente, 53,3 e 57 indivíduos.

Essa maior abundância nas profundidades $2-4$ e $4-6 \mathrm{~cm}$ pode ter ocorrido em virtude de uma maior vazão do rio em julho que resulta nesta migração dos indivíduos. As profundidades 6-8 e 8-10 cm permaneceram com as menores médias de abundância sugerindo que os níveis de oxigênio são baixos nesses estratos. 
Em outubro, foi contabilizado no ponto 3 valores bem menores de abundância meiofaunística em comparação a julho. Apesar disso, a triagem de outubro revelou um comportamento da abundância semelhante ao observado em julho neste mesmo ponto. A profundidade mais abundante foi a $2-4 \mathrm{~cm}$ com 37,7 indivíduos, seguida da profundidade $4-6 \mathrm{~cm}$ com 28,7 indivíduos e da $0-2 \mathrm{~cm}$ com 27 . A profundidade $6-8 \mathrm{~cm}$ teve uma quantidade relativamente alta (26,3 indivíduos) se comparada às outras profundidades mais superficiais e a profundidade 8-10 cm teve em média 6,3 indivíduos.

Figura 12 - Perfis de abundância média da meiofauna por profundidade no Ponto 3

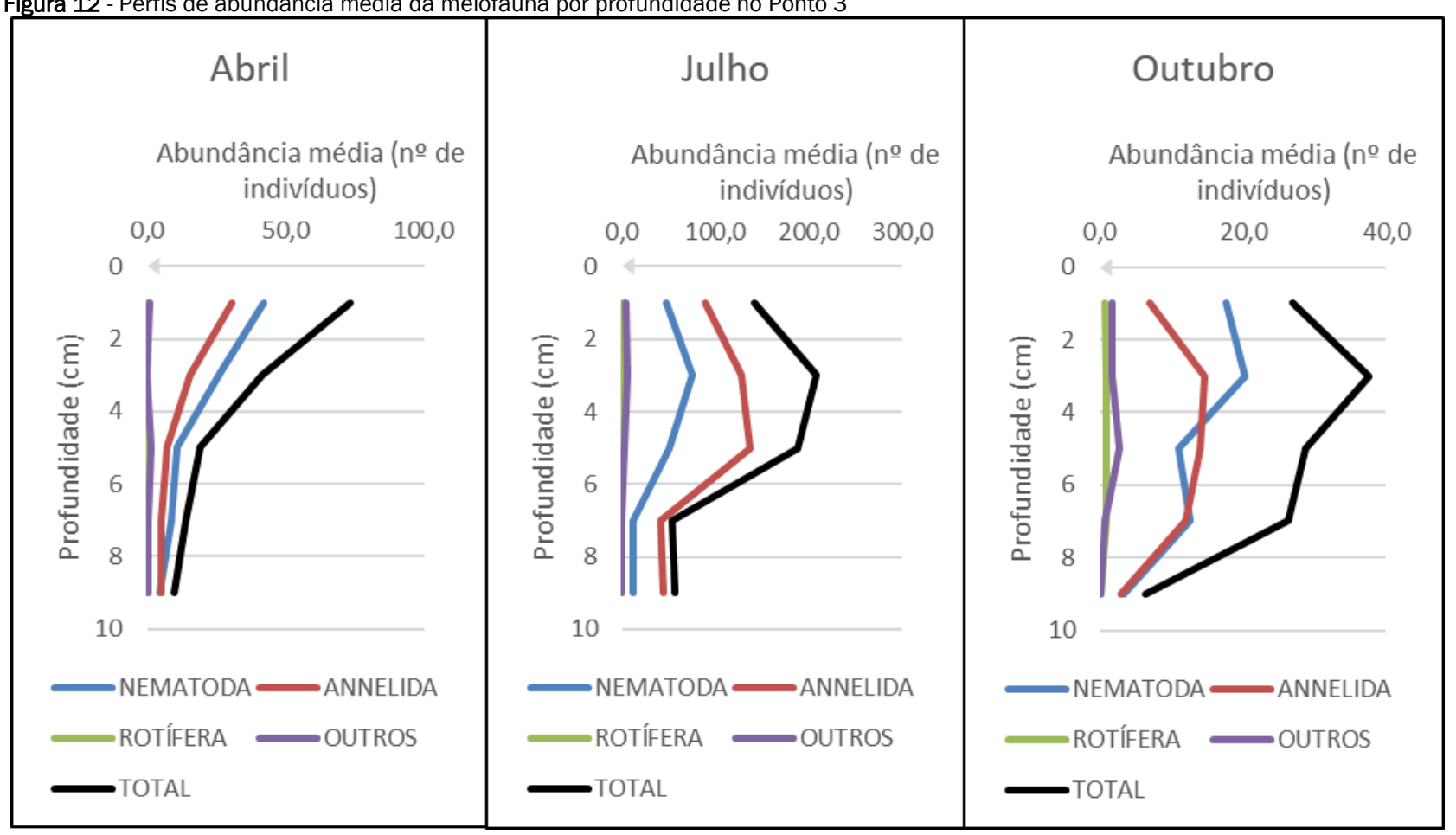

Em geral, pode-se concluir que as camadas mais superficiais (até $6 \mathrm{~cm}$ ) foram responsáveis pela maior abundância comparado com as camadas mais profundas (de 6 a $10 \mathrm{~cm}$ ). Este resultado foi semelhante ao encontrado por Veras et al. (2018), que em 2016 analisou a meiofauna nos mesmos pontos no rio Beberibe nas profundidades $0-5 \mathrm{~cm}$ e $5-10 \mathrm{~cm}$, encontrando um número maior de indivíduos na camada $0-5 \mathrm{~cm}$.

Diferentemente, Traunspurger, Threis e Madji (2015) observaram que as camadas $5-10 \mathrm{~cm}$ foram mais abundantes do que camada superficial em dois rios na Alemanha, provavelmente porque os leitos destes rios são ricos em cascalho, facilitando a infiltração da água superficial na camada $5-10 \mathrm{~cm}$.

Além disso, semelhantemente ao observado por Pacioglu e Robertson (2017) em estudo realizado em rios britânicos, as variações sazonais de fluxo do rio e a diferença de carga hidráulica entre o rio e o aquífero não influenciaram significantemente no comportamento da distribuição vertical da meiofauna.

Apesar disso, os dados apresentados neste artigo mostram que o decréscimo da abundância com a profundidade nem sempre aconteceu de forma gradativa, quando a meiofauna é analisada em camadas de $2 \mathrm{~cm}$.

\section{CONCLUSÕES}

A pesquisa contabilizou na zona hiporreica de trechos do rio Beberibe um total de 4906 organismos da meiofauna de 8 grupos taxonômicos, entre os quais os mais encontrados foram os Nematoda, Annelida e Rotifera.

A partir dos perfis de abundância média, observou-se um maior número de indivíduos nos primeiros $6 \mathrm{~cm}$ de profundidade, o que é bastante compreensível devido a maior quantidade de oxigênio e matéria orgânica disponível nestas camadas.

Porém, a diminuição da abundância média não se deu gradativamente em todos os pontos, sendo visto por vezes abundâncias maiores em camadas inferiores em relação à camada mais superficial $(0-2 \mathrm{~cm})$.

Provavelmente isto ocorreu por ação de um maior hidrodinamismo em decorrência do regime pluviométrico, como aconteceu no período chuvoso (em julho) nos pontos 2 e 3 . Pode ter ocorrido ainda em virtude de condições de rio influente, ou seja, com fluxo descendente na interação rio-aquífero, onde a água superficial rica em oxigênio se infiltra no aquífero subjacente, como observado no início do período chuvoso (em abril) no ponto 1 .

A ação do hidrodinamismo do rio foi analisada considerandoa como resposta direta do regime pluviométrico e a condição de fluxo vertical (ascendente ou descendente) foi constatada a partir da utilização de piezômetro diferencial. Estes dois fatores foram muito úteis para análise da distribuição vertical da meiofauna, embora os resultados não tenham comprovado um vínculo completamente determinante entre eles. 
Ademais, foi notado que os grupos taxonômicos não variaram consideravelmente entre si com a profundidade, fazendo com que os comportamentos das variações de abundância média fossem muito parecidos entre eles.

As conclusões do presente trabalho indicam que o comportamento da comunidade da meiofauna hiporreica pesquisada em trechos da bacia hidrográfica do rio Beberibe é bastante complexo e, em consequência disso, também é complexa sua distribuição vertical.

O regime pluviométrico e o piezômetro diferencial foram boas ferramentas de análise desta distribuição, porém sugere-se novos estudos que fornecem de informações que possam ajudar na previsibilidade do comportamento desta classe de organismos.

\section{REFERÊNCIAS}

APAC - Agência Pernambucana de Água e Clima. Monitoramento Pluviométrico. Disponível em: http://www.apac.pe.gov.br/meteorologia/monitoramentopluvio.php, 2018.

ALBUQUERQUE, T.B.V. Caracterização física e biológica da Zona Hiporreica na interação rio-aquífero no Rio Beberibe-PE. Tese (Doutorado em Engenharia Civil) - Universidade Federal de Pernambuco, Recife - PE, 2015.

ALVARES, C.A.; STAPE, J. SENTELHAS, P.; GONÇALVES, J.L.; SPAROVEK, G. Köppen's climate classification map for Brazil. Metereologische Zeitschrift, v. 22, n. 6. p.711-728, 2013.

BARA, M.K.; VELISKOVA, Y.; DULOVICOVA, R.; SCHUGERL, R. Influence of surface water level fluctuation and river bed sediment deposits on groundwater regime. J Hydrol, v.62, p.177185, 2014.

BARCELLOS, R.L.; FLORES-MONTES, M.J.; ALVES, T.M.F.; CAMARGO, P.B. Modern sedimentar processes and seasonal variations of organic matter in na urban tropical estuary, Jaboatão River (PE), Brazil. Journal of Coastal Research, v. 75, p. 3842, 2016.

CABRAL, J.J.S.P.; KOIDE, S.; SIMOES, S.; MONTENEGRO, S. M. G. L. Recursos Hídricos Subterrâneos. In: PAIVA, J.B.D; PAIVA, E.M.C.D. Hidrologia Aplicada à Gestão de Pequenas Bacias Hidrográficas. 1.ed.Porto Alegre: ABRH, v. 1, p.237-277, 2001.

COULL, B.C. Role of meiofauna in estuarine soft-bottom habitats. Australian Journal of Ecology. 24, p. 327-343, 1999.

CAMPOS, H.L. Processo Hidrológico de Gestão na Bacia Hidrográfica do Rio Beberibe (PE): uma retrospectiva. Tese (Doutorado) - Universidade Federal do Rio de Janeiro, Instituto de Geociências. 226p., 2003.

CHEN, X.; SONG, J.; CHENG, C.; WANG, D.; LACKEY, S.O. A new method for mapping variability in vertical seepage flux in streambeds. J Hydrol, v. 17, p. 519 - 525, 2008.
GIERE, O. Meiobenthology: the miscroscopic motile fauna of aquatic sediments. SecondEdition. Springer. 2009.

HAKENKAMP, C.C.; PALMER, M.A.The ecology of hyporheic meiofauna. In: JONES, J.B., MULHOLLAND, P.J. Streams and groundwaters. Academic Press. Cap. 13, p. 307-329, 2000.

HANNAH, D.; KRAUSE,S.; FLECKENSTEIN, J.; HEPPELL. K. et al. Biogeochemistry and the hydroecology of the hyporheic zone. In: ENVIRONMENTAL AGENCY. The Hyporheic Handbook. Science Report: SC050070. Chapter 5. October, 2009.

HARGUINTEGUY, C.A.; COFRÉ, M.N.; WARD, C.T. Change in the meiofauna community structure of sandy beaches of the Nuevo Gulf (Chubut, Argentina). Papéis Avulsos de Zoologia, v. 52, n. 34, p. 411-422, 2012.

INMET - Instituto Nacional de Meteorologia. $3^{\circ}$ Distrito de Meteorologia (DISME). Boletim com a Normal Climatológica no período 1961 a 1990, 2003.

LIU, Y.; DEDIEU, K.; SANCHEZ-PÉREZ, J.; MONTUELLE, B. et al. Role of biodiversity in the biogeochemical processes at the water-sediment interface of macroporous riverbed: An experimental approach. Ecological Engineering, v. 103, part B, p. 385-393. 2017.

LU, C.; CHEN, X.; OU, G.; CHENG, C. Determination of the anisotropy of na upper stream bed layer in east-central Nebraska, USA. Hydrogeology Journal, v.20, p.93-101, 2012.

MARIA, T.F.; WANDENESS, A.P.; ESTEVES, A.M. State of the art of the meiofauna of Brazilian Sandy Beaches. Brazilian J. Oceanography, 64, p. 17-26, 2016.

MUGNAI, R.; MESSANA, G.; DI LORENZO, T. The hyporheic zone and its functions: revision and research status in Neotropical regions. Resultados da pesquisa. Brazilian Journal of Biology. v. 75 , n. 3, p. 524-534. 2015.

PALMER, M.A. Hydrodynamics and structure: interactive effects on meiofauna dispersal. Journal of Experimental Marine BiologyandEcology, v.104, p.53-68, 1986.

PACIOGLU, O.; ROBERTSON, A. The invertebrate community of the chalk stream hyporheic zone: spatio-temporal distribution patterns. Knowledge \& Management of Aquatic Ecosystems, v.418, n.10, 2017

REEDER, W.J.; QUICK, A.M.; FARRELL, T.; BENNER, S.; FERIS, K.; TONINA, D. Spatial and temporal dynamics of dissolved oxygen concentrations and bioactivity in the hyporheic zone. Water Resources Research, v. 54, n. 3, p. 2112-2128, 2018.

SIRH - Sistema Integrado de Recursos Hídricos e Energéticos. Secretaria de Recursos Hídricos. http://www.sirh.srh.pe.gov.br/site Acesso em 2017.

TRAUNSPURGER, W.; THREIS, I.; MAJDI, N. Vertical and temporal distribution of free-living nematodes dwelling in two sandy- 
bed streams fed by helocrene springs. Nematology, v.17, n.8, p.923-940, 2015.

TUFENKJI, N.; RYAN, J. N.; E ELIMELECH, M. Bank filtration: a simple technology may inexpensively clean up poor-quality raw surface water. Environmental Science and Technology, p. 423$428,2002$.

VERAS, T.B.; CABRAL, J.J.S.P. ; PAIVA, A.L.R. ; BARCELLOS, R.L. ; SANTOS, L.L. . Vertical hydraulic gradient research in hyporheic zone of Beberibe river in Pernambuco State (Brazil). RBRH, v. 21, p. 674-684, 2016.
VERAS, T.B.; CABRAL, J.J.S.P.; PAIVA, A.L.R; BARRETO, A.F.S. Interação rio-aquífero e a meiofauna do ambiente hiporreico. Águas Subterrâneas, v. 31, n.1, p.20-35, 2017.

VERAS, T.B.; CABRAL, J.J.S.P.; PAIVA, A.L.R.; SANTOS, P.J.P; FREITAS, D.A. Evaluation of Meiofauna in the Hyporheic Zone of the Beberibe River, Pernambuco, Brazil. Water Environment Research, v. 90, n, 8, p. 685-696, 2018.

WARD, J.V.; PALMER, M.A. Distribution patterns of interstitial freshwater meiofauna over a range of spatial scales, with emphasis on aluvial river-aquifer systems. Hydrobiologia, v.287, p. 147-156, 1994. 